\title{
Síndrome de Bloom: relato de dois casos
}

\section{Bloom syndrome: two cases report}

Aline Salmito Frota ${ }^{1}$. Aline de Moura Brasil Matos ${ }^{2}$. Verônica Riquet de Siqueira Lima ${ }^{1}$. Hercília Maria Carvalho Queiroz ${ }^{1}$. Jéssica Gomes Carneiro ${ }^{1}$. Carlos Henrique de Oliveira Araújo ${ }^{1}$. Juliana Maria Cavalcante Ribeiro Ramos ${ }^{3}$. José Wilson Accioly Filho ${ }^{4}$.

1 Dermatologista, residência no Hospital Universitário Walter Cantídio (HUWC), Universidade Federal do Ceará (UFC), Fortaleza-CE, Brasil. 2 Residente de Neurologia do Hospital Geral de Fortaleza, Fortaleza-CE, Brasil. 3 Residente de Dermatologia do Hospital Universitário Walter Cantídio (HUWC), Universidade Federal do Ceará (UFC), Fortaleza-CE, Brasil. 4 Dermatologista, professor, preceptor da residência e chefe do Serviço de Dermatologia do Hospital Universitário Walter Cantídio (HUWC), Universidade Federal do Ceará (UFC), Fortaleza-CE, Brasil.

\section{RESUMO}

Síndrome de Bloom é uma doença autossômica recessiva caracterizada por eritema telangiectásico em face, fotossensibilidade e retardo de crescimento pré e pós-natal. A mutação do gene BLM, traz uma instabilidade cromossômica importante, responsável pelas manifestações da síndrome e pela maior susceptibilidade a neoplasias. Há um registro mundial de pacientes com um total de 255 casos, sendo 16 do Brasil. Diante da raridade da síndrome, apresentamos o caso de duas irmãs, filhas de pais consanguíneos, ambas com baixa estatura, apresentando máculas eritematosas com telangiectasias em nariz e região perioral, micrognatismo, dolicocefalia, hipoplasia malar, face triangular, nariz proeminente, máculas hipocrômicas e manchas café com leite em tronco e membros inferiores. O diagnóstico é clínico e pode ser confirmado por citogenética. Os portadores apresentam fenótipo típico com telangiectasias em áreas fotoexpostas. Ainda não há tratamento específico, porém, deve-se oferecer suporte clínico e melhoria da qualidade de vida e diminuição de estigmas.

Palavras chave: Síndrome de Bloom. Eritema telangiectásico congênito. Eritema. Telangiectasia.

\section{ABSTRACT}

Bloom's syndrome is an autosomal recessive disorder characterized by telangiectatic erythema in the face, photosensitivity and growth retardation. BLM gene mutation brings an important chromosomal instability, responsible for the manifestations and the higher susceptibility to cancer. A global registry of patients comprises a total of 255 cases, 16 from Brazil. Due to the rarity of the syndrome, we present the case of two sisters, daughters of consanguineous parents, both with short stature and erythematous macules with telangiectasias in the nose and perioral region, micrognathia, dolichocephaly, malar hypoplasia, triangular face, prominent nose, hypochromic macules and café au lait spots on the trunk and lower limbs. The diagnosis is clinical and can be confirmed by cytogenetics. The patients have typical phenotype with telangiectasias on sun-exposed areas. There is still no specific treatment, however, supportive care should be offered, associated with an improvement of the quality of life and reduction of stigma.

Keywords: Bloom syndrome. Congenital telangiectatic erythema. Erythema. Telangiectasis.

Autor correspondente: Aline Salmito Frota, Universidade Federal do Ceará. Rua Nunes Valente, 1352, apto 102, Aldeota, Fortaleza, Ceará. CEP: 60125-070. Telefone: +55 (85) 99913-9916/98676-9916. E-mail: alinesalmito@hotmail.com.

Conflito de interesses: Não há qualquer conflito de interesses por parte de qualquer um dos autores.

Recebido em: 26 Mar 2015; Revisado em: 31 Mai 2015; Aceito em: 08 Jun 2015. 


\section{INTRODUÇÃO}

Síndrome de Bloom (SB), ou Eritema Telangectásico Congênito, é uma doença autossômica recessiva caracterizada principalmente por eritema telangiectásico na face, fotossensibilidade e retardo de crescimento pré e pós natal. $^{1,2}$ A mutação do gene BLM, responsável pela codificação de uma das helicases RecQ, faz com que os portadores da síndrome apresentem instabilidade cromossômica importante, responsável pelas manifestações da síndrome e pela maior susceptibilidade a neoplasias, em especial a linfomas. ${ }^{3,4}$

É mais comum em homens e em judeus ashkenazi. Há alterações cromossômicas, com quebras e rearranjos, sendo as mais características as configurações quadrirradiais e as trocas de cromátides irmãs. ${ }^{5}$

Na diagnose diferencial, temos lúpus eritematoso sistêmico, síndrome de Rothmund-Thomson, síndrome de Cockayne e ataxia telangiectasias, doenças que podem cursar com telangiectasias e fotossensibilidade. ${ }^{5}$

Esta rara síndrome, descrita inicialmente por David Bloom em 1954, teve um registro mundial de pacientes criado na década de 1960, o Bloom's Syndrome Registry, que conta com um total de 255 casos, sendo 16 originários do Brasil. ${ }^{6,7}$

Ainda não há cura para a síndrome, no entanto, abordagens para melhoria de qualidade de vida e diminuição de estigmas são propostos, como abordagem dermatológica das telangiectasias de face. Recomenda-se fotoproteção rigorosa e acompanhamento para detecção precoce de neoplasia que possam surgir. ${ }^{5}$

A prognose é reservada pelo possível aparecimento de neoplasias malignas e pela imunodeficiência, que podem levar a óbito antes da quinta década de vida.

\section{RELATO DOS CASOS}

Caso 1: JSM, 20 anos de idade, sexo feminino, natural e procedente de São Gonçalo do Amarante, nasceu a termo, com peso de $1700 \mathrm{~g}$ e estatura: $43 \mathrm{~cm}$. Procurou atendimento médico, por apresentar desde o primeiro ano de vida, máculas eritematosas em face, hiperemia na região palpebral superior e inferior bilateral, associado a dor e prurido, além de um quadro de dermatite seborréica associado, com boa acuidade visual. Tinha história de uma internação por pneumonia, além de diarreia, desnutrição e otalgia frequente com hipoacusia bilateral. Ao longo do seu desenvolvimento, observou-se déficit estatural e ponderal, face estreita e delicada; nariz, orelhas e dentes protrusos, além da persistência das lesões cutâneas citadas anteriormente, dificuldade no aprendizado. Menarca aos 12 anos de idade com ciclos menstruais regulares. Pais são consanguíneos (primos legítimos). Ao exame físico, observou-se máculas eritematosas com telangiectasias no nariz, região perioral e fronte, onde há discreta atrofia da pele. Micrognatismo, dolicocefalia, hipoplasia malar, face triangular, nariz proeminente, ausência de cílios na pálpebra inferior, mamas e genitália externa pouco desenvolvidas, baixa estatura (134cm). Máculas hipocrômicas manchas café com leite, configurando as twin-spots (Figuras 1-2). Apresenta exames laboratoriais, dosagem hormonal, US tireoide e abdome e ecocardiograma sem alterações. Biópsia (17/09/2002): epiderme aplainada com hiperceratose, hipergranulose discreta e vacuolização da basal, com dilatação dos capilares na derme superior que encontra-se associada a presença de exsudato moderado de linfócitos em faixa, melanófagos na derme papilar. Após primeira internação, em 2002, foi encaminhada para parecer da genética, oftalmo, endócrino e pediatria.

Figura 1. Eritema telangiectásico na região centro-facial e ausência de cílios pálpebra inferior.

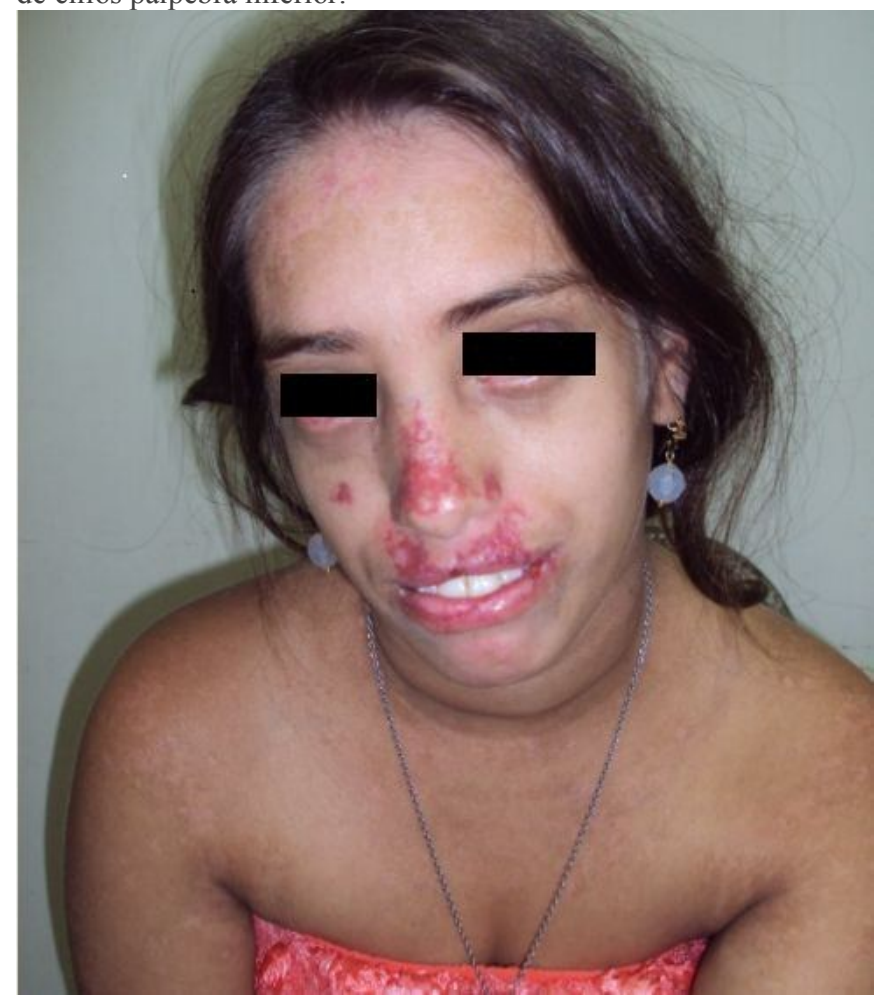

Figura 2. Máculas hipocrômicas e manchas café com leite - twin spots.

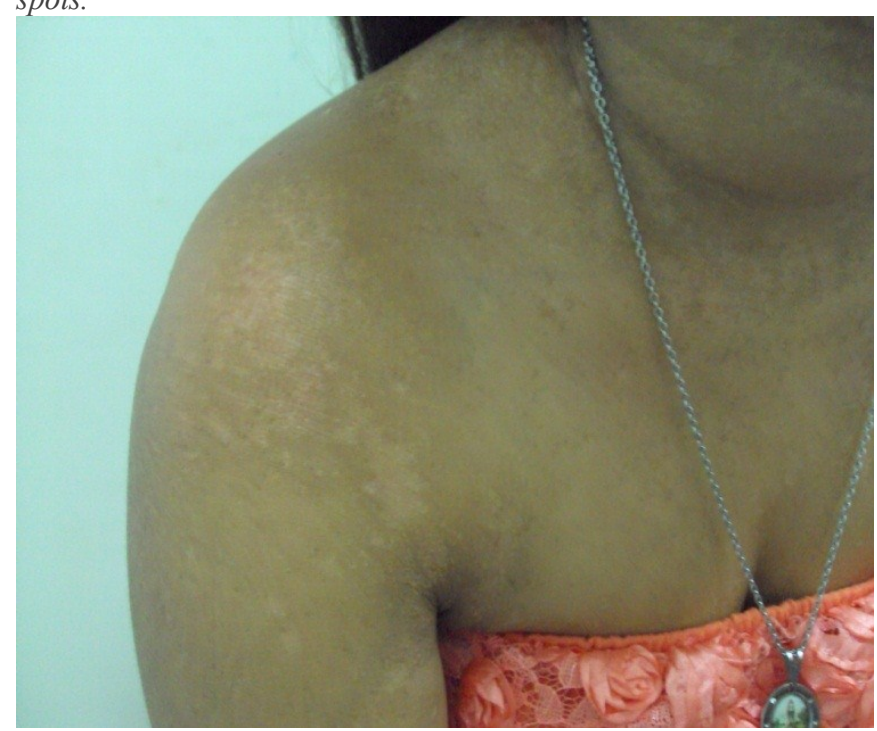


Caso 2: MSM, 7 anos, sexo feminino, natural e procedente de São Gonçalo do Amarante. Mãe informa que criança nasceu com $1800 \mathrm{~g}$, estatura de $44 \mathrm{~cm}$, andou com 10 meses. Iniciou com 1 ano de idade, máculas eritematosas na fronte, dorso do nariz e bochechas e região perioral, com discreto prurido. Bom desenvolvimento neuropsicomotor. Ao exame físico: déficit estatural $(102 \mathrm{~cm})$, máculas eritematosas no nariz e na região perioral, rarefação de cílios na pálpebra inferior, fácies semelhante a da irmã, manchas café com leite em MMII e tronco (Figuras 3-6). Exames laboratoriais de 2007 sem alterações.

Figura 3. Eritema telangiectásico e micrognatismo.

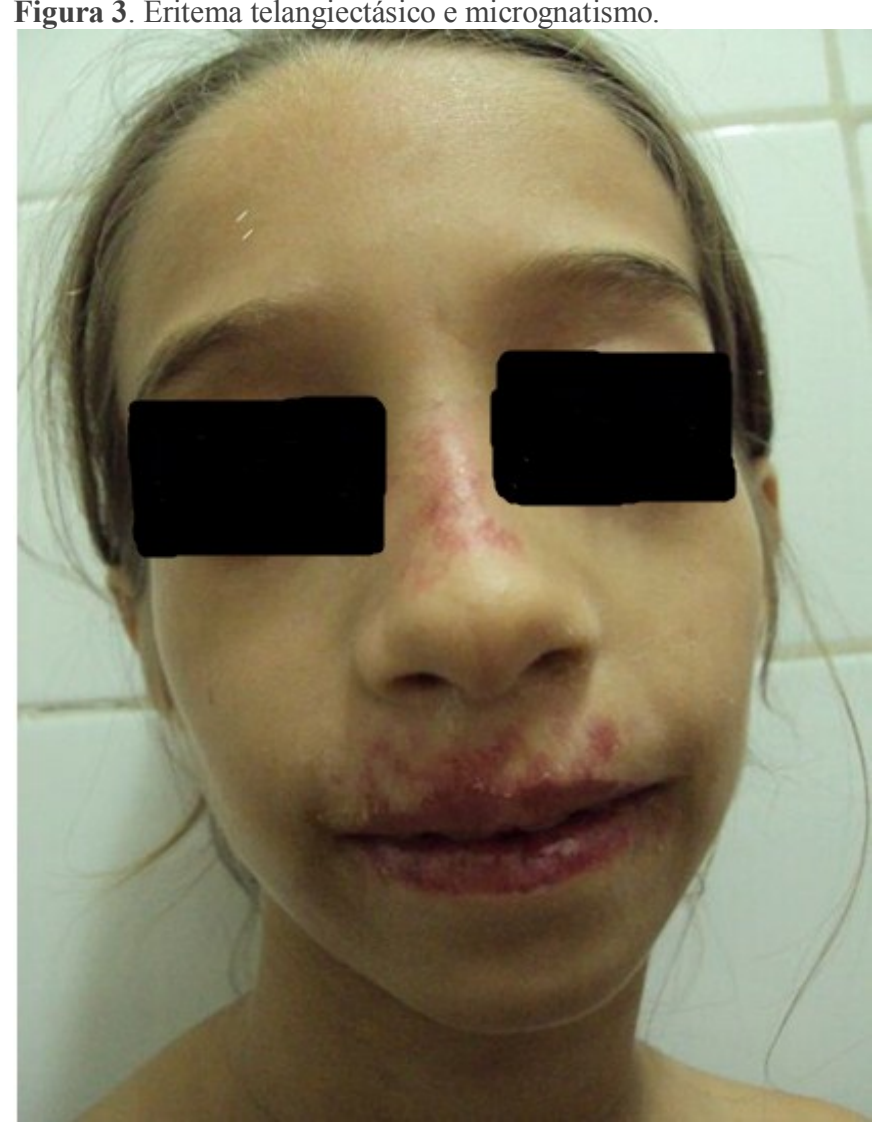

Figura 4. Dolicocefalia.

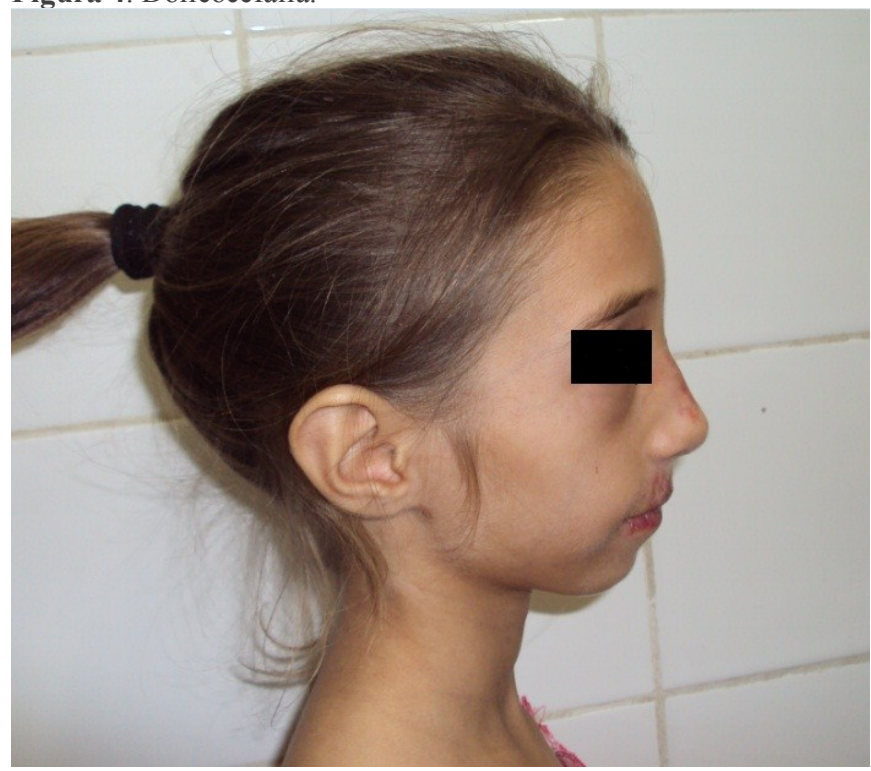

Figura 5. Manchas café com leite e máculas hipocrômicas no tronco.

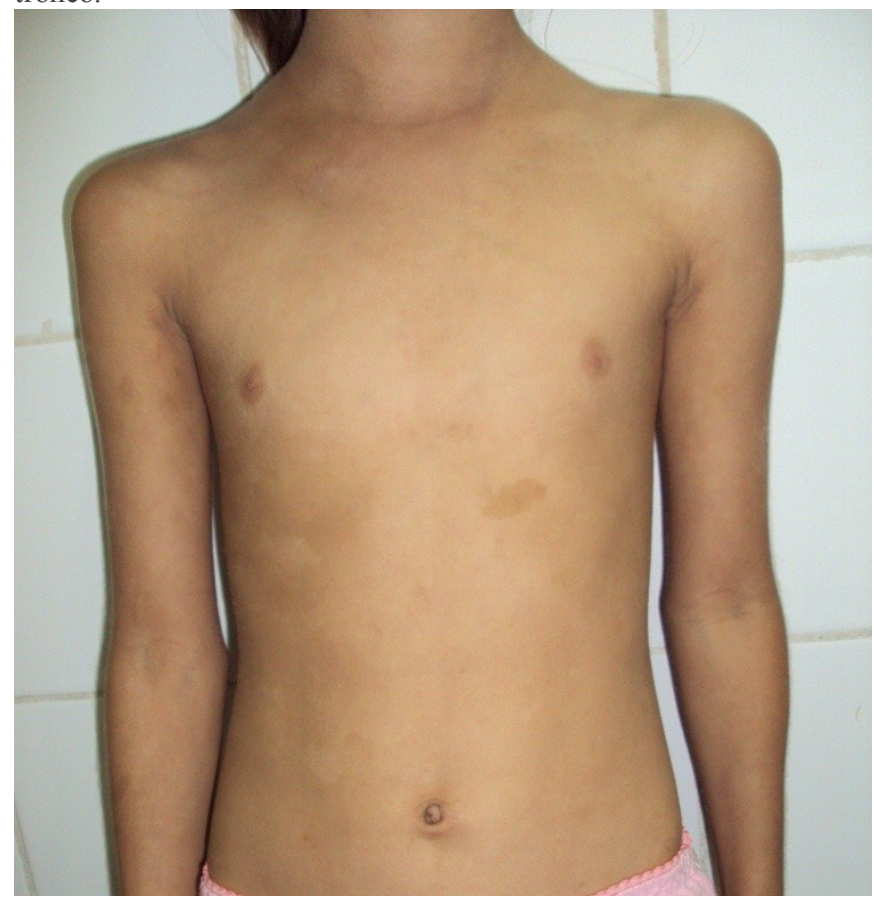

Figura 6. Manchas café com leite nos membros inferiores.

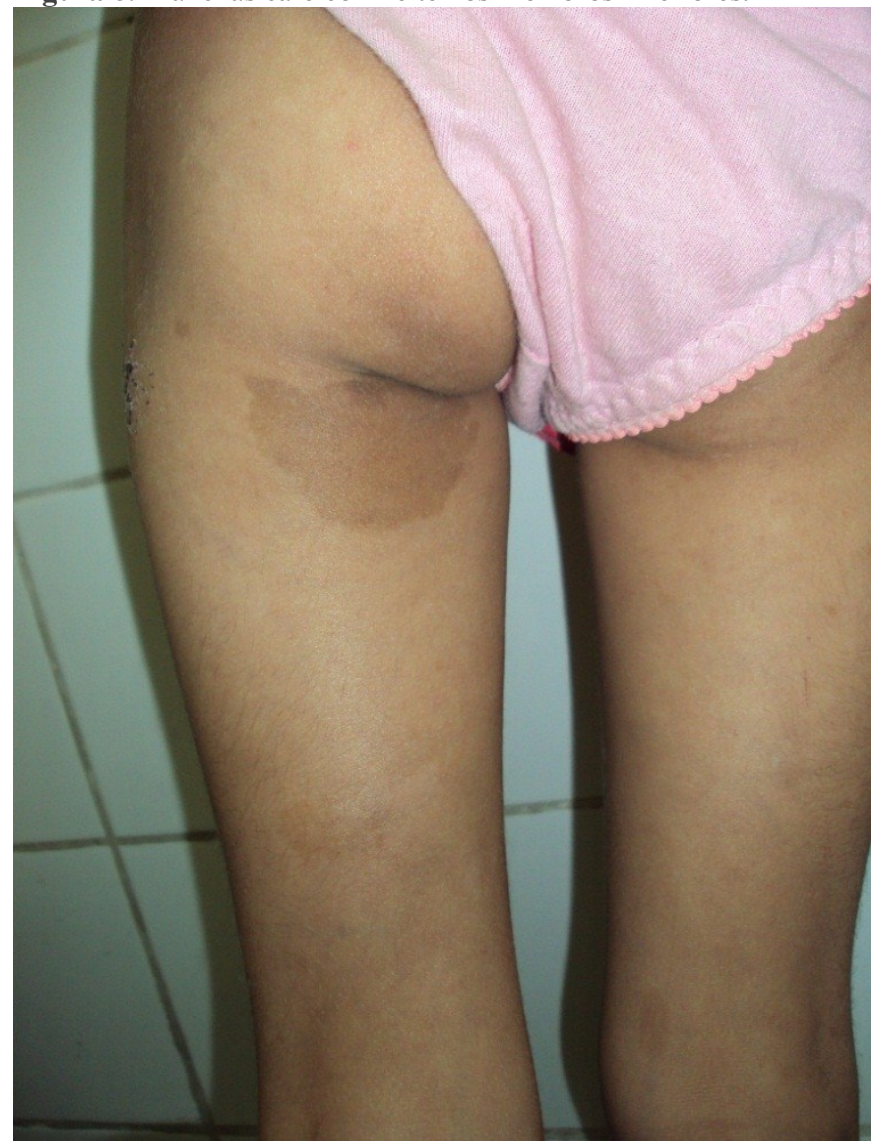

\section{DISCUSSÃO}

O diagnóstico da rara Síndrome de Bloom é clínico e citogenético. Os portadores da síndrome apresentam fenótipo típico, marcado por telangiectasias, principalmente no nariz, região malar, fronte, lábios, orelhas e mais raramente dorso 
de mãos e braços. ${ }^{1} \mathrm{O}$ eritema surge nos primeiros dias de vida, assumindo configuração em vespetilho. ${ }^{5}$ As lesões de pele tendem a tornar-se menos graves quando o indivíduo envelhece, mas às vezes cicatrizes, atrofia, despigmentação de pele e perda dos cílios são aparentes e desfigurantes. Os indivíduos apresentam uma face delicada e estreita, com microcefalia desproporcional, alguns apresentam timbre vocal estridente. ${ }^{1}$ Existem relatos ainda de displasias ósseas, presença de manchas café-com-leite, alterações dentárias e alterações oculares. ${ }^{8}$

O histopatológico mostra atrofia da epiderme com retificação dos cones epiteliais, degeneração hidrópica da camada basal, incontinência pigmentar e infiltrado mononuclear perivascular, ${ }^{5}$ alguns desses achados sendo encontrados no exame da paciente do caso 1 .

Haja vista a alteração genética causadora da síndrome, é marcante a grande incidência de neoplasias nestes indivíduos, que chegam a apresentar risco 150 a 300 vezes maior de desenvolver algum tipo de malignidade quando comparados a população não portadora, sendo as mais comuns as hematológicas e as de origem epitelial, ${ }^{9}$ sendo por este motivo importante o seguimento clínico a longo prazo. Também pode ocorrer imunodeficiências. ${ }^{5}$

O gene BLM, alterado na síndrome, está localizado no cromossoma 15 (15q26.1 lócus) e codifica 1417 BLM aminoácido (RECQL3), proteína homóloga a helicases RecQ. O resultado desta alteração é um grande aumento na ocorrência de recombinações homólogas (crossing-over) e células filhas com material genético distinto do material da célula de origem. ${ }^{3,9}$

Infecções do trato gastro intestinal e infecções respiratórias de repetição com resposta débil a antibioticoterapia levaram à investigação imunológica de vários portadores da SD, observando-se baixos níveis de CD4+, IgM e IgA de modo variável nos pacientes. Existem relatos isolados de resposta insatisfatória a imunizações vacinais polissacarídicas e casos de necessidade de suporte ventilatório em unidade intensiva por lesão pulmonar importante, possivelmente por alteração de parênquima pulmonar após anos de processos infecciosos de repetição. ${ }^{8-11}$

Alterações de fertilidade (homens inférteis e mulheres com fertilidade reduzida) e puberdade precoce, ainda sob investigação, são até então relacionados a aumento dos níveis de FSH em ambos sexos. ${ }^{8,9}$

\section{REFERÊNCIAS}

1. German J. Bloom's syndrome. I. Genetical and clinical observations in the first twenty seven patients. Am J Hum Genet. 1969;21(2):196-227.

2. Sultan SJ, Sultan ST. Bloom syndrome in two siblings. Pediatr Dermatol. 2010;27(2):174-7.

3. Ellis NA, Sander M, Harris CC, Bohr VA. Bloom's syndrome workshop focuses on the functional specificities of RecQ helicases. Mech Ageing Dev. 2008;129(11):681-91.
No registro mundial de pacientes portadores, organizado por Bloom e German, há uma alta incidência de Diabetes Mellitus tipo 2 (DM 2). Entre junho de 1999 e junho de 2003, médicos do New York Presbyterian Hospital, ${ }^{12}$ avaliaram esta e outras endocrinopatias em pacientes com a síndrome. No estudo, todos os pacientes maiores de 10 anos apresentaram alteração da tolerância a glicose ou DM 2. Alguns apresentaram hipotireoidismo compensado, todos tinham secreção normal do hormônio do crescimento $(\mathrm{GH})$, e a maioria era hiperlipidêmica. A fertilidade não foi avaliada.

As síndromes genéticas autossômicas recessivas são marcadas pela sensibilidade a radiação UV-B (290 - 315 $\mathrm{nm})$. Para a SB há uma sensibilidade específica ao comprimento de onda de $313 \mathrm{~nm}$, que é próxima a radiação UV-A. É interessante pontuar que estas radiações causam um efeito fototóxico nos pacientes com Bloom, sem o efeito fotocarcinogênico, como observado no xeroderma pigmentoso. $\mathrm{Na} \mathrm{SB}$, não é observado aumento de sensibilidade a radiação $\mathrm{X}^{13}$ A histopatologia das lesões encontradas nestes pacientes são descritas como lesões lupus-like, como as vistas no relato de caso de McGowan e nas descrições iniciais de Giannelli. ${ }^{13,14}$

A avaliação citogenética, parte do diagnóstico proposto pelo Bloom's Syndrome Registry, pode ser realizada através da técnica $G$ bands ou pelo método Sister Chromatid Exchange (SCE), neste encontramos uma enorme quantidade de troca de cromátides irmãs no estudo de culturas de linfócitos. ${ }^{7,8}$

O tratamento da síndrome consiste em suporte clínico, uso de fotoprotetores, acompanhamento regular para flagrar surgimento de neoplasias e para cuidados com processos infecciosos de repetição. Além disso, é proposto o tratamento de fenótipos estigmatizantes da síndrome, como as telangiectasias de face. Embora não exista relato na literatura do uso desta terapia para pacientes com SB, é interessante a investigação do benefício do uso da terapia a laser para a redução das telangiectasias, pois, como vimos, o comprimento de onda danoso aos pacientes com SB está abaixo daqueles utilizados na terapia a laser, tais como: Copper Vapor/Bromide Laser (578 nm, amarelo), Potassium Titanyl Phosphate (532 nm, verde), Pulsed Dye Laser (585$600 \mathrm{~nm}$, amarelo), Diode (800, 810, 940, 980 nm, próximo ao infra-vermelho), $N d: Y A G\left(1,064 \mathrm{~nm}\right.$, infra-vermelho). ${ }^{5,15}$

4. German J. Bloom's syndrome. XX. The first 100 cancers. Cancer Genet Cytogenet. 1997;93(1):100-6.

5. Sampaio SAP, Rivitti EA. Dermatologia. 3. ed. São Paulo: Artes Médicas; 2007. Capítulo 70, Doenças poiquilodérmicas, displasias ectodérmicas e doenças pigmentares hereditárias; p. 1075-94.

6. Gretzula JC, Hevia O, Weber PJ. Bloom's syndrome. J Am Acad Dermatol. 1987;17(3):479-488. 
7. Bloom's Syndrome Registry [Internet]. New York: cWeill Cornell Medical College; [date unknown] - [acesso 2013 set 05]. Disponível em: http://weill.cornell.edu/bsr/

8. Masmoudi A, Marrakchi S, Kamoun H, Chaaben H, Ben Salah G, Ben Salah R, et al. Clinical and laboratory findings in 8 patients with Bloom's syndrome. J Dermatol Case Rep. 2012;6(1):29-33.

9. Puzianowska-Kuznicka M, Kuznicki J. Genetic alterations in accelerated ageing syndromes. Do they play a role in natural ageing? Int J Biochem Cell Biol. 2005;37(5):947-60.

10. Roxo P Júnior, Menezes UP, Ferriani VP, Sorensen RU. Immunodeficiency phenotypes in two siblings with Bloom Syndrome. Rev Bras Alerg Imunopatol. 2007;30(1):32-5.

11. Nair G, Lobo I, Jayalaksmi TK, Uppe A, Jindal S, Chandra A, et al. Bloom syndrome with lung involvement. Lung India. 2009;26(3):92-4.
12. Diaz A, Vogiatzi MG, Sanz MM, German J. Evaluation of short stature, carbohydrate metabolism and other endocrinopathies in Bloom's syndrome. Horm Res. 2006;66(3):111-7.

13. McGowan J, Maize J, Cook J. Lupus-like histopathology in bloom syndrome: reexamining the clinical and histologic implications of photosensitivity. Am J Dermatopathol. 2009;31(8):786-91.

14. Giannelli F, Pawsey SA, Botcherby PK. Tendency to high levels of UVR-induced unscheduled DNA synthesis in bloom syndrome. Mutat Res. 1981;81(2):229-41.

15. Hare McCoppin HH, Goldberg DJ. Laser treatment of facial telangiectases: an update. Dermatol Surg. 2010;36(8):1221-30.

\section{Como citar:}

Frota AS, Matos AM, Lima VR, Queiroz HM, Carneiro JG, Araújo CH, et al. Síndrome de Bloom: relato de dois casos. Rev Med UFC. 2015 jan-jun;55(1):52-56. 